\title{
The Effect of the Explicit Instruction of Formulaic Sequences in Pre-Writing Vocabulary Activities on Foreign Language Writing
}

\author{
Dina Abdel Salam El-Dakhs (Corresponding author) \\ Prince Sultan University, Saudi Arabia \\ E-mail: ddakhs@psu.edu.sa \\ Tanecia Tasneem Prue \\ Prince Sultan University, Saudi Arabia \\ Attia Ijaz \\ Prince Sultan University, Saudi Arabia
}

Received: 22-11-2016

Published: 01-07-2017
Accepted: 24-01-2017

doi:10.7575/aiac.ijalel.v.6n.4p.21
Advance Access Published: April 2017

URL: http://dx.doi.org/10.7575/aiac.ijalel.v.6n.4p.21

\begin{abstract}
The present study investigates the effect of the explicit instruction of formulaic sequences in pre-writing vocabulary activities on foreign language writing. To this end, a total of 81 Saudi pre-intermediate learners of English as a foreign language participated in a 10-week study of a pretest/posttest design. In every 2-hour session of a total of 10 sessions, the participants were required to read a news story and then re-write it individually without looking back at the original story. During the treatment period, the participants received different pre-writing vocabulary practice. One group, consisting of 44 students, practiced individual words in the news stories while the remaining 37 students studied formulaic sequences in the new stories before re-writing the stories in their own language. Analyzing the students' writing showed that the explicit instruction of formulaic sequences led to an increased use of the sequences in students' writing. The results also partially supported a positive influence for the explicit instruction of formulaic sequences on the learners' lexical choices and overall writing quality. The practice provided on formulaic sequences in the study did not, however, result in any significant improvement in the learners' use of formulaic sequences in autonomous story rewriting. Relevant pedagogical implications are proposed.
\end{abstract}

Keywords: formulaic sequences, foreign language writing, explicit instruction, vocabulary teaching, pre-writing tasks, writing instruction

\section{Introduction}

Vocabulary knowledge is a prerequisite for writing (e.g., Li and Schmitt, 2009; Yonek, 2008). It is through words that ideas are communicated, opinions shared and thoughts conveyed. In fact, lack of good vocabulary knowledge constitutes a major barrier to communication, particularly in academic writing (e.g., Santos, 1988). It is hence generally believed that having a rich vocabulary repertoire is a major advantage for writers, particularly if they possess good command of the constituent elements of this repository. Sinclair (1991) makes a distinction between two approaches to vocabulary generation that language users employ in their production. One approach allows users to select single words independently to fit clauses. Each position in the clause then represents a choice for the user who needs to fill with a word to their liking. The approach was thus termed "the open choice principle." The other approach, however, may seem much less creative as the user retrieves complex chunks from memory. Choices hence are highly reduced as multiword expressions, also known as formulaic sequences, dominate the scene and "the idiom principle" emerges. As Sinclair (1991) puts it, "the principle of idiom is that a language user has available to him a large number of semipreconstructed phrases that constitute single choices, even though they might appear to be analysable into segments," (110).

Formulaic sequences, chunks, multi-word expressions and semi-preconstructed phrases are only a few terms used to refer to the phrases under the idiom principle. Other regularly used terms to describe the same phenomenon are prefabricated language, lexical bundles, formulaic language, lexical phrases and prefabs among others. These formulaic sequences, the term used in this paper, have been recurrently defined (e.g., Wood, 2002; Erman and Warren, 2000; Wray, 2000). A suitable definition for the present paper is "[sequences], continuous or discontinuous, of words or other elements linked together, which are, or appear to be, prefabricated: that is, stored and retrieved whole from memory at the time of use, rather than being subject to generation or analysis by the language grammar," (465). Different classifications have been put forward for such sequences, including Lewis's (1997) into words and polywords, 
collocations, institutionalized utterances and sentence frames and heads, Erman and Warren's (2000) into lexical prefabs, grammatical prefabs, pragmatic prefabs and reducibles, and Stengers, Boers, Housen and Eyckmans's (2011) into collocations, idioms, binomials, standardized similes, proverbs and clichés, discourse organizers and social routine formulae. The main characteristics for formulaic sequences in the present paper are that they represent (1) combinations of words; (2) frequent co-occurrences; (3) continuous or non-continuous word sequences; (4) semantically transparent or opaque multi-word structures; and (5) wholes that seem to be retrievable as single units. Illustrative examples can be "impose sanctions," "raining cats and dogs," "salt and pepper," "clear as crystal," "Too many cooks spoil the broth," "Having said that," and "How do you do?"

Forming an important part of the lexicon (e.g., Martinez and Schmitt, 2012), formulaic sequences have been found fundamental to the way language is used, processed and acquired (e.g., Alali and Schmitt, 2012; Wood, 2002). The benefits of mastering formulaic sequences have been repeatedly cited in the literature (e.g., Durrant, 2008; Wray, 2000). For example, Martinez and Schmitt (2012) highlight four key benefits for formulaic sequences that were also supported by empirical evidence; (1) making up a large proportion of any discourse (e.g., 58.6\% of spoken text and $52.3 \%$ of written text by Erman and Warren (2000), (2) realizing a multitude of meanings and functions (e.g., signposts of discourse organization like "on the other hand," and commonly believed truths such as "Money talks"), (3) promoting efficient and effective communication as formulaic language is easier and faster to understand and produce (e.g., Conklin and Schmitt, 2008; Jiang and Nekrasova, 2007), and (4) enhancing productive fluency (e.g., Guz, 2014). The proven centrality of this phenomenon to communication has called for investigating its use by second/foreign language learners whose effective and efficient language use highly relies on adequate knowledge of formulaic language.

Unfortunately, it is now widely acknowledged that second/foreign language learners demonstrate great difficulty generating native-like and appropriate formulaic sequences (e.g., Gómez Burgos, 2015; Xu and Zhang, 2015; Shi and Wang, 2015; Chen and Baker, 2010). This leads to drastic effects on their production, particularly in writing, as their poor use of formulaic sequences may lead to increased and sustained processing burdens for readers (e.g., Millar, 2001), notable differences than native speakers' academic discourse (e.g., Dontcheva-Navratilova, 2012) and lower scores in composition classes (e.g., Ohlrogge, 2009). It is thus generally believed that second/ foreign language classes (e.g., Dontcheva-Navratilova, 2012; Ohlrogge, 2009), and particularly writing classes (e.g., Xu and Zhang, 2015; Alali and Schmitt, 2012; Erman and Warren, 2000), must address formulaic sequences to support second/foreign language learners. The question is: How can this be achieved? In other words, what are the effective strategies to practice formulaic sequences in writing classes?

The above question constitutes the motivation for the present study, which examines one suggested strategy; i.e., the explicit instruction of formulaic sequences in pre-writing activities. The study investigates the effect of this strategy on enhancing the foreign language learners' use of formulaic sequences and the overall quality of their writing. In fact, incorporating pre-writing vocabulary activities in the foreign language writing class is a common practice. However, there is no principled way to integrate formulaic language in the teaching activities (e.g., Murray, 2016; Martinez and Schmitt, 2012; Ylisirniö, 2012; Koprowski, 2005). It is much more common to practice individual words in the prewriting tasks (e.g., 'critical', 'sanctions' and 'dialogue') instead of formulaic sequences (e.g., 'in critical condition', 'impose sanctions' and 'engage in direct dialogue'). The present study compares the effect of the explicit instruction of individual words versus formulaic sequences in pre-writing activities on foreign language writing. It is hoped that the incorporation of formulaic sequences in pre-writing activities can provide a much-needed scaffold for foreign language learners, enhance their use of native-like chunks, improve their lexical choices and boost the overall quality of their writing.

\section{Literature Review}

Examining the explicit instruction of formulaic sequences in second/foreign language classes has recently attracted increased attention. Among the common lines of research are the effect of explicit versus implicit teaching mode on language learners' formulaic sequences in the second language (L2) classroom (e.g., Shamsaee, Hashemi, Yoonessi and Ghapanchiz, 2015), how similar the teaching of formulaic sequences is to that of single words (e.g., Alali and Schmitt, 2012), the effect of explicit instruction of formulaic sequences on incidental noticing of further formulaic sequences (e.g., Mueller, 2010), the reading comprehension ability (e.g., Abbasian, 2012), speaking fluency (e.g., Afzali, 2015) and/or pragmatic competence (e.g., Zavialova, 2015), the development of phrasal expressions lists to support the systematic integration of formulaic sequences in language learning (e.g., Martinez and Schmitt, 2012) and the longitudinal development of formulaic language (e.g., Li and Schmitt, 2009). The present section is restricted to review recent studies on the explicit instruction of formulaic sequences in writing classes, which represents the focus of the current study.

Relevant studies in the literature have addressed formulaic sequences in general, focused on specific types of sequences and/or investigated the effect of particular teaching modes. A sample study that addressed formulaic sequences in general is Čolović-Marković's (2012). The doctoral dissertation examined the effect of explicit instruction of formulaic sequences on L2 writing through a quasi-experimental design. The experimental $(\mathrm{N}=27)$ and control $(\mathrm{N}=17)$ groups were recruited from the writing classes of an intensive English program preparing students for academic writing at a US university. Both groups had the same amount of instruction time over 8 weeks, shared the same syllabus, materials, composition assignments and instructor, and demonstrated similar language proficiency (high-intermediate level), but belonged to different language backgrounds (e.g., Arabic, Japanese, French, Spanish, Thai, Russian, Portuguese, etc.). The two groups were exposed to formulaic sequences in background reading and class discussions prior to writing, but 
only the experimental group was engaged in systematic explicit instruction of the academic and topic-induced formulaic sequences in order to raise their awareness and encourage their use of these sequences in production. The results showed that explicit instruction helped enhance declarative knowledge as the experimental group was better able to produce academic and topic-induced formulaic sequences in C-tests. As for essay-writing, representing uncontrolled production, the experimental group, particularly the low-level learners, benefitted from the explicit instruction as they produced the sequences they were exposed to in their writing. However, no statistical difference was found between the experimental and controlled groups in terms of quality of writing. It must be noted though that the experimental group were allowed access to the background reading materials and taught formulaic sequences while preparing their essays and were clearly asked to incorporate these sequences in their essays. Hence, the use of the sequences reflects better awareness and recognition of the target patterns rather than efficient recall.

Another case in point is Latifi and Afraz's study (2015) which investigated the effect of explicit instruction of lexical bundles on developing the writing skills of pre-intermediate EFL (=English as a Foreign Language) learners. A homogeneous group of 50 Iranian EFL learners were recruited for the study purpose from a language school. The students' proficiency was assessed at a pre-intermediate level and their ages ranged between 21 and 29. Their performance on the pre-test was similar, which further supported the homogeneity of the group. The students were equally divided into an experimental group and a control group for a period of three months. While the experimental group received explicit instruction for one third of each writing class time on the use of lexical bundles before writing essays, the control group was involved in conventional pre-writing activities with no practice of lexical bundles. The experimental group members were also allowed to practice the use of bundles both in class and at home. The post-test revealed significant improvement in writing performance for the experimental group suggesting the effectiveness of explicit instruction of lexical bundles in EFL writing classes.

Other studies, however, addressed specific patterns of sequences. For example, Ergĭn (2013) examined the effect of explicit teaching of multi-word metadiscourse markers (e.g., in other words, on the one hand and as well as) on the writing performance of Turkish EFL learners. A total of 31 university students of upper-intermediate proficiency level participated in the study. The participants' age was around 18 and all of them were enrolled in an English language literature program. Employing a quasi-experimental research design, the participants were divided into an experimental group who received explicit instruction of the target discourse markers for 8 hours over 4 weeks and a control group who did not receive any formulaic language training during the same period. Comparing the participants' performance at the pre- and post-tests, which was an essay explaining their opinion regarding the importance of foreign language learning, it was revealed that the experimental group outperformed the control group in terms of the use of discourse markers as well as their overall writing performance. The study thus provided support for the effectiveness of explicit formulaic language instruction on foreign language writing. Positive influence for explicit instruction of metadiscourse markers on EFL learners' writing performance was also found in other studies (e.g., Dastjerdi and Shirzad, 2010).

In the same vein, Kazemi, Katiraei and Rasekh (2014) examined the effect of explicit teaching of discipline-specific lexical bundles on writing and students' attitudes to this teaching mode. To this end, 20 Iranian advanced EFL learners enrolled in a Master's program in TEFL (=Teaching English as a Foreign Language) participated in the study. Prior to the treatment, the participants wrote a pre-test essay on the role of vocabulary in EFL reading comprehension. Then, they received explicit instruction on 40 lexical bundles of most frequency, relevance and functionality in the field of Applied Linguistics. The training lasted for four 90-minute sessions over a month. This was followed by a post-test essay and a questionnaire regarding the students' views on the treatment. The results highlighted the positive impact of the intervention on students' writing. In addition, the students' views on the intervention came highly in favor as they appreciated the significance of the target bundles to enhance their writing.

Other studies have addressed specific teaching modes with regards to formulaic language in writing classes. For instance, Nasiri and Khorshidi (2015) examined the effect of a new approach to assessment, known as dynamic assessment, on the teachability of formulaic sequences in writing classes and hence on the overall writing quality. Dynamic assessment (DA) was defined in the study in terms of dynamic interaction between the examiner and examinee as the first offers support to the latter through leading questions and prompts. Hence, this assessment approach involves both instruction and assessment. To assess the effect of the approach on EFL learners' writing, an intact group of 20 Iranian advanced EFL learners with an average age of 25 were selected for the study upon ensuring their homogeneity. After a pre-test, the group underwent relevant DA mediation over 16 weeks with clear focus on their use of formulaic sequences in writing. Upon the completion of the mediation practice, a post test was administered and compared with the pre-test. Two experienced raters were involved in the comparison and their inter-rater reliability was confirmed. The results showed a positive effect for the merging of instruction and assessment on the formulaic sequence use in writing. The researchers highlighted various benefits for the DA as it improved formulaic sequence production, involved students in learning, increased students' motivation and decreased their test-taking nervousness.

Similarly, Chun-guang (2014) investigated the effect of corpus-driven lexical chunks teaching on EFL writing. A total of 60 undergraduates who were non-English major and enrolled at the freshmen level participated in the study. They were divided into three groups of proficiency (i.e., high, medium and low) based on the pre-test results. The treatment, which lasted for 2 years, involved improving the learners' awareness of lexical chunks and the use of corpora, training them on autonomous learning of chunks and encouraging them to use and consolidate the chunks in their production. Data collection involved other 4 post-test essays, interviews and a questionnaire. The results showed that corpus-driven lexical chunks teaching led to an increase in the number of lexical chunks in learners' writing and a rise in their writing 
scores. A positive relationship was in fact found between the use of chunks and writing scores. It was also found that the higher the proficiency level of the learners, the better their ability to properly employ lexical chunks in their writing. The researcher suggests giving high priority to lexical chunks in teaching writing to achieve idiomaticity and fluency.

The present study examines the effect of teaching formulaic sequences in foreign language writing classes. The study is not restricted to specific types of sequences as the selection of target sequences varies based on the background reading texts. The study aims to examine the effect of explicit instruction of formulaic sequences in pre-writing activities on the writing of students in terms of incorporation of sequences in their writing, their lexical choices, the overall quality of writing and their ability to autonomously identify and use formulaic language in writing. The study also aims to compare the effect of formulaic language instruction with traditional vocabulary instruction in the pre-writing stage. It is important to find out if the pre-teaching of formulaic sequences in writing classes is of better impact than the preteaching of individual words as is the case in traditional writing instruction.

\section{Research Questions}

The present study addresses four research questions with reference to the explicit instruction of formulaic sequences in EFL writing classes:

1. Does the explicit instruction of formulaic sequences in pre-writing tasks lead to increased use of formulaic sequences in students' writing?

2. Does the explicit instruction of formulaic sequences versus individual words in pre-writing tasks lead to better lexical choices in students' writing?

3. Does the explicit instruction of formulaic sequences versus individual words in pre-writing tasks lead to higher overall students' writing scores?

4. Does the explicit instruction of formulaic sequences in pre-writing tasks lead to a subsequent increase in autonomous use of formulaic sequences in students' writing?

\section{Methodology}

\subsection{Setting and participants}

The present study was conducted in four classes of the preparatory year program (PYP) at a private university in Riyadh, Saudi Arabia. The PYP aims to prepare students for the academic demands of university education through enhancing their English language proficiency along with other relevant skills such as computer skills. The English component of the program is composed of three levels (i.e., beginners, elementary and pre-intermediate), each of which lasting for an academic semester of 15 weeks. University applicants sit for an admission test that assesses their English language competence and hence assigns them to one of the three levels or allows them to proceed to university programs directly after writing a 5-paragraph essay in one hour. University applicants can also skip the English program at the PYP upon passing an IELTS exam with a score of 5.5.

The present study was implemented at the pre-intermediate level. The students study 20 hours of English per week, including classes of reading and writing, listening and speaking, grammar, English for Specific Purposes and extensive reading. The extensive reading class is known as the reading circle and lasts for 2 hours each week. This class proved the most convenient for the study purpose since the instructors could afford to assign students further extensive reading activities at home while designating the class time for implementing the study. The four classes were taught by 4 different teachers, all of whom possess extensive experience teaching EFL classes. Three of the teachers hold a Master's Degree in language studies while the fourth is CELTA certified. Two teachers are native speakers of British English while the other two possess native-like competency. The teachers' age ranged between 28 and 40 with an average of 35 . They were adequately trained in foreign language instruction and largely applied communicative approaches to language teaching.

The participants of the study constituted 81 Saudi female learners. Their English language proficiency level was assessed at a pre-intermediate level as mentioned earlier, and they were all native speakers of Arabic with an average age of 19. Their educational background was also homogenous as they had been studying at Saudi schools prior to university admission. The participants were informed of the study purpose and design prior to implementation and expressed consent to participate as they could see the benefit of the additional reading and vocabulary activities.

\subsection{Research design}

In order to compare the effect of teaching formulaic sequences versus individual words in pre-writing tasks, an experimental design was adopted including pre-test, treatment and post-test. In the pre-test, all participants read a news story and discussed answers to comprehension questions as a whole class. The reading and classroom discussion took almost 40 minutes of class time. The students were then asked to re-write the story individually in not less than 150 words and without looking back at the original story. The writing task was assigned 30 minutes and was not preceded by any vocabulary activities.

Unlike the pre-test, the treatment period, which lasted for 8 weeks, involved students in vocabulary activities at the prewriting stage. Every week, during the assigned class, the participants read a news story and discussed answers to comprehension questions as a whole class. The story and comprehension questions were unified across the 4 classes. The participants were then engaged in vocabulary activities on individual words or formulaic sequences extracted from the news stories. Two classes, composed of 44 students, practiced individual words (IW) only while the other two 
classes, consisting of 37 students, solely practiced formulaic sequences (FS). For example, while the IW group focused on "suicide", "tears", "viral" and "autopsy", the FS group practiced "in critical condition", "suicide bomber", "tears roll down her face", "go viral" and "autopsy results". After the vocabulary exercises, all participants were asked to follow the same writing pattern of the pre-test; i.e., re-writing the story individually without looking back at the original story within 30 minutes and in not less than 150 words.

Similar to the pre-test, the post-test required the participants to read a news story and discuss comprehension questions in a classroom discussion. Without any pre-writing vocabulary activities, the students then engaged in re-writing the story individually for 30 minutes and in not less than 150 words without looking back at the original story.

The researchers chose this design to assess the effect of the teaching of formulaic sequences versus individual words at the pre-writing stage on the students' writing production. Comparing the performance of the two groups (i.e. IW and FS) at the treatment stage, on the one hand, will address the first three study questions regarding the effect of the explicit instruction of formulaic sequences in pre-writing tasks on the use of formulaic sequences, lexical choices and overall scores in writing. Comparing the pre-test and post-test, on the other hand, will assess the effect of the treatment on the students' autonomous story re-writing.

\subsection{Materials and instruments}

The researchers, two of whom are PYP instructors, selected the study reading texts from the CNN news stories published online at http://edition.cnn.com/. Students' interest was considered as per the judgment of the PYP instructors and also through selecting updated news stories. The selected texts were posted online between October 2014 and April 2015 while the study was conducted between February and May 2015. The topics of the text are listed in the table below:

Table 1. Titles of CNN news stories used in the experiment

\begin{tabular}{ll}
\hline Pre-Test & Trafficked Chinese boy reunited with family after 24 years apart \\
\hline & Sisters charged with killing older brother \\
\cline { 2 - 2 } Treatment & $\begin{array}{l}\text { Harvard professor sorry for fighting restaurant over \$4 } \\
\text { Nigerian mosque attack death toll climbs over 100 scores more hurt }\end{array}$ \\
\cline { 2 - 2 } & Malala's journey from near death to the Nobel Peace Prize \\
\cline { 2 - 2 } & Buried in snow for 7 hrs, boys feared death \\
\cline { 2 - 2 } & Man reunites with stolen dog during search for new pet \\
\hline Post-Test & Grandmother has made her way in Egypt's work world - as a man \\
\hline
\end{tabular}

The texts, ranging in length between 450 and 850 words, were adapted by the PYP instructors to suit the students' language competence. The adaptation, which mainly included incorporating easier words and simpler structures, depended on the PYP instructors' discretion after long years teaching students at the PYP Program. After the adaptation of texts, the researchers chose 20 formulaic sequences and 20 individual words for each text to teach at the pre-writing stage of the treatment period (see Appendix A for sample target vocabulary). The choice of the formulaic sequences was based on the available sequences in the texts that were judged to be in common use by the researchers while the individual words were selected from among the sequences. For example, the individual words "premeditated" and "asleep" were selected from the sequences "premeditated murder" and "fall asleep". It is worth noting that the target vocabulary, whether IW or FS, in the treatment texts were emboldened and underlined in the news stories to increase the participant's noticing.

All the texts were followed by comprehension questions to support the participants' comprehension of the texts. The questions were all wh-questions that ranged between 4 and 7 questions per text. While constructing the questions, the researchers ensured that the questions covered all main parts of the news stories and were also phrased in a way that students could understand. As for the treatment texts, 4 vocabulary exercises (mainly, matching, gap-filling, paraphrasing and sentence construction) were also added after the comprehension questions and before the writing tasks. The exercises were again constructed by the researchers to ensure unification across all the participants.

The final task, the writing task, always stated the following: "Without looking back to the news item, re-write the story in one or two paragraphs. Your writing should not be less than 150 words. You have 30 minutes." A 4-scale rubric was devised to assess the students' writing (see Appendix B). The rubric, assessing content, organization, lexical choice, mechanics and sentence structure, was devised by the researches and validated through the PYP teaching staff.

\subsection{Data collection procedures}

A meeting was held with the instructors prior to the pre-test to familiarize them with the aim of the study and explain the procedure of implementation. The instructors were given clear directions orally and in writing and were invited to 
seek clarification or provide any comments before the implementation of the study. It was clearly communicated to the instructors that it is of great importance to follow the sequence of activities designed for the texts and other relevant instructions, such as the timing of the writing task, to maximize consistency among the four classes. Instructors were also able to easily access the researchers throughout the study for any queries.

Prior to the experiment, the class instructors introduced the students to the experiment and explained that it is conducted as part of a research study to enhance the teaching of writing. The general design and procedure of the experiment were communicated to the students who agreed to participate in the study mainly to read interesting news stories and benefit from the additional vocabulary practice. After seeking the students' consent, the experiment lasted for 10 weeks; one for the pre-test, eight for the treatment and one for the post-test. The experiment was thus implemented once a week for the period of 10 weeks, with each session lasting for almost two hours. The reading part with the comprehension questions often lasted around 40 minutes, the vocabulary exercises about 20 minutes and the writing 30 minutes. The remaining time involved giving/ checking instructions and discussing the results of students' earlier writing.

Four observations are worth mentioning about the writing task. First, the students were introduced to the writing rubric prior to the experiment as part of familiarizing them with the experiment procedure. Second, the students were not allowed to look back at the news stories while re-writing the summary to assess their ability to recall the target vocabulary. Third, the students were not required to include the vocabulary in the pre-writing tasks in their actual writing. The choice of words in the story re-writing was left totally up to the students' discretion. Finally, the students' writing was regularly corrected by the researchers using the set rubric and passed on to the students through their teachers. The regular feedback aimed to provide continuous input to students and enhance their engagement in the experiment. For additional motivation, an average score for the writing tasks counted for the students' grade on the reading circle class. The researchers' scoring of the writing helped reduce additional burdens on the class instructors and maximize consistent scoring.

In preparation for the statistical treatment, the researchers kept record of two types of data based on their analysis of the students' writing. First, the formulaic sequences in the writing tasks were identified, counted and recorded. This was mainly to address the first research question concerning the effect of explicit instruction on the use of formulaic sequences in writing. Second, the researchers' assessment of the students' writing using the study rubric was maintained and also offered for statistical analysis. It is worth nothing that the assessment was made by the two researchers teaching at the PYP who are both Master's degree holders and have vast experience in teaching EFL writing. Each paper was marked by the two researchers and compromise was reached in case of disagreement.

\section{Results}

The first research question "Does the explicit instruction of formulaic sequences in pre-writing tasks lead to increased use of formulaic sequences in students' writing?" was addressed through comparing the number of formulaic sequences the students recalled from the news stories they had read and produced in their writing tasks. The comparison was made between the FS and the IW groups per every text using T-test as shown in Table (2). The T-test results show that both the FS and IW groups used formulaic sequences from the news stories in their written texts. However, a clear advantage is noted for the FS group throughout the 8 weeks with a statistical significance of 0.000 . It must also be noted that the highest mean for FS stood at 8.54 for the FS group in text 7 while the lowest mean for FS was 2.16 for the IW group in text 2 .

Table 2. The effect of FS explicit instruction on their use in writing

\begin{tabular}{|c|c|c|c|c|c|}
\hline Text & Group & Mean & S.D. & T-Test & Sig \\
\hline \multirow[t]{2}{*}{1} & FS & 4.89 & 2.356 & 4.295 & 0.000 \\
\hline & IW & 2.78 & 1.974 & 4.343 & \\
\hline \multirow[t]{2}{*}{2} & FS & 5.56 & 2.771 & 6.432 & 0.000 \\
\hline & IW & 2.16 & 1.734 & 6.615 & \\
\hline \multirow[t]{2}{*}{3} & FS & 7.58 & 3.144 & 6.183 & 0.000 \\
\hline & IW & 3.53 & 2.603 & 6.257 & \\
\hline \multirow[t]{2}{*}{4} & FS & 6.38 & 2.672 & 4.964 & 0.000 \\
\hline & IW & 3.48 & 2.485 & 4.987 & \\
\hline \multirow[t]{2}{*}{5} & FS & 7.30 & 3.751 & 6.796 & 0.000 \\
\hline & IW & 2.56 & 2.107 & 7.027 & \\
\hline \multirow[t]{2}{*}{6} & FS & 6.59 & 3.045 & 7.587 & 0.000 \\
\hline & IW & 2.55 & 1.172 & 7.557 & \\
\hline \multirow[t]{2}{*}{7} & FS & 8.54 & 2.674 & 4.476 & 0.000 \\
\hline & IW & 5.97 & 2.398 & 4.508 & \\
\hline \multirow[t]{2}{*}{8} & FS & 7.35 & 3.125 & 5.217 & 0.000 \\
\hline & IW & 3.76 & 2.972 & 5.234 & \\
\hline
\end{tabular}

The second research question, "Does the explicit instruction of formulaic sequences versus individual words in prewriting tasks lead to better lexical choices in students' writing?" was addressed through comparing the scores for lexical choice among the FS and IW groups across the 8 texts using T-test as shown in Table (3). The T-test results show an 
advantage for the FS group in lexical choice in 4 out of the 8 conditions. The FS group received significantly higher scores for lexical choice in texts 3, 4, 5 and 6 while the FS and IW groups performed equally in the remaining texts.

Table 3. The effect of FS explicit instruction on lexical choices in writing

\begin{tabular}{|c|c|c|c|c|c|}
\hline Text & Group & Mean & St.Dev. & T-Test & Sig \\
\hline \multirow[t]{2}{*}{1} & FS & 2.4766 & .524533 & .842 & .402 \\
\hline & IW & 2.3276 & 1.00633 & .818 & \\
\hline \multirow[t]{2}{*}{2} & FS & 2.5180 & .51788 & 1.324 & .189 \\
\hline & IW & 2.2819 & 1.01966 & 1.285 & \\
\hline \multirow[t]{2}{*}{3} & FS & 2.7179 & .58220 & 2.577 & .012 \\
\hline & IW & 2.2727 & .93787 & 2.520 & \\
\hline \multirow[t]{2}{*}{4} & FS & 3.1622 & .51861 & 2.977 & .004 \\
\hline & IW & 2.6970 & .85376 & 2.908 & \\
\hline \multirow[t]{2}{*}{5} & FS & 2.7241 & .58001 & 3.456 & .001 \\
\hline & IW & 2.1563 & .87331 & 3.389 & \\
\hline \multirow[t]{2}{*}{6} & FS & 2.6471 & .62008 & 2.451 & .016 \\
\hline & IW & 2.2273 & .89840 & 2.408 & \\
\hline \multirow[t]{2}{*}{7} & FS & 2.5143 & .77684 & .143 & .886 \\
\hline & IW & 2.4839 & 1.10578 & .141 & \\
\hline \multirow[t]{2}{*}{8} & FS & 2.7838 & .50049 & -1.148 & .255 \\
\hline & IW & 2.9079 & .46288 & -1.152 & \\
\hline
\end{tabular}

The third research question, "Does the explicit instruction of formulaic sequences versus individual words in prewriting tasks lead to higher overall students' writing scores?" was again addressed using a T-test comparison between the FS and IW groups regarding their overall writing scores. The T-test results shown in Table (4) reveal that the FS group outperformed the IW group in three texts (i.e., 3, 4 and 6) while the IW group exhibited higher scores in text 8 . No statistically significant difference was noted in the other texts.

Table 4. The effect of FS explicit instruction on overall writing scores

\begin{tabular}{|c|c|c|c|c|c|}
\hline Text & Group & Mean & St.Dev. & T-Test & Sig \\
\hline \multirow[t]{2}{*}{1} & FS & 13.1488 & 2.37072 & 1.063 & .291 \\
\hline & IW & 12.3286 & 4.31558 & 1.027 & \\
\hline \multirow[t]{2}{*}{2} & FS & 12.4719 & 2.40412 & -.334 & .739 \\
\hline & IW & 12.7500 & 4.75511 & -.321 & \\
\hline \multirow[t]{2}{*}{3} & FS & 13.2055 & 2.47110 & 2.072 & .042 \\
\hline & IW & 11.5000 & 4.64280 & 1.999 & \\
\hline \multirow[t]{2}{*}{4} & FS & 15.6762 & 2.50905 & 2.380 & .020 \\
\hline & IW & 13.9092 & 4.00252 & 2.314 & \\
\hline \multirow[t]{2}{*}{5} & FS & 13.7241 & 2.69504 & .804 & .424 \\
\hline & IW & 13.1407 & 3.72535 & .788 & \\
\hline \multirow[t]{2}{*}{6} & FS & 14.4567 & 2.79888 & 2.632 & .010 \\
\hline & IW & 12.3878 & 4.13308 & 2.570 & \\
\hline \multirow[t]{2}{*}{7} & FS & 14.0198 & 2.60233 & .167 & .868 \\
\hline & IW & 13.8676 & 5.22402 & .161 & \\
\hline \multirow[t]{2}{*}{8} & FS & 13.6488 & 2.43166 & -2.023 & .047 \\
\hline & IW & 14.9827 & 3.40033 & -1.981 & \\
\hline
\end{tabular}

The fourth and final question, "Does the explicit instruction of formulaic sequences in pre-writing tasks lead to a subsequent increase in autonomous use of formulaic sequences in students' writing?," was addressed through a Ttest comparison between the number of formulaic sequences the FS group employed in their pre- and post-tests. The T-test results, shown in Table (5), do not reveal any statistical significance.

Table 5. The effect of explicit FS instruction on subsequent autonomous FS use in writing

\begin{tabular}{lllll}
\hline Test & Mean & St.Dev. & T-value & Sig \\
\hline Pre & 4.38 & 1.238 & .228 & .821 \\
Post & 4.28 & 2.764 & & \\
\hline
\end{tabular}




\section{Discussion}

The study results have clearly indicated that the explicit FS instruction in pre-writing activities leads to an increase in students' use of these formulaic sequences in their writing even if not required to use them as is the case in the present study. In fact, the difference was highly significant in all 8 texts in favor of the FS group who always produced a higher number of proper formulaic sequences based on the background readings. This finding comes in line with the repeated calls in the literature (e.g., Xu and Zhang, 2015; Alali and Schmitt, 2012; Erman and Warren, 2000) for explicit instruction of formulaic sequences in writing classes. Foreign learners, at least at the pre-intermediate level, do not seem capable of identifying relevant sequences in readings and using them in writing independently without instructional intervention. The average use of the IW group of formulaic sequences throughout the 8 texts stood at 3.3 per text whereas the FS group's average was 6.7 . This discrepancy could be safely contributed to the instructional intervention at the treatment period.

Two other observations must be noted in relation to the use of formulaic sequences by the FS group. First, the highest mean for the use of proper formulaic sequences by the FS group was 8.54 in text (7). Considering this mean in light of the fact that 20 formulaic sequences were explicitly taught to the students for each text shows the difficulty of incorporating formulaic sequences that had just been taught in pre-writing activities in immediately subsequent writing tasks, particularly that the students were not allowed access to the reading texts or the vocabulary activities at the time of writing. It did not seem easy for students to recall the sequences and then properly incorporate them in writing. Second, the mean of formulaic sequences in the first two texts (i.e., in the range of 4 to 5) is lower than the mean for later texts ranging between 6 and 8. This may reflect increasing confidence in the use of sequences with repeated practice.

The use of formulaic sequences in writing should serve as a means, not an end. It should be a means to improve the students' writing performance. In the present study, T-test comparisons were made between the FS and IW groups to assess their lexical choices in writing and their overall writing performance as a result of the treatment phase. Improvement was noted at the two fronts with the FS group outperforming the IW group in 4 out of 8 texts for lexical choices and in 3 out of 8 texts in overall writing performance. The scores for the remaining texts showed no statistical significance except for one text where the IW group was rated higher for the overall writing score. This improvement is still considered significant considering that the treatment introduced new formulaic sequences in each text, that the students practiced the sequences for a relatively short time prior to writing, and that the students had to recall the sequences since they had no access to the texts while writing. This treatment was notably different than earlier studies that proved the effectiveness of FS instruction at a larger scale. For example, Latifi and Afraz (2015) allowed longer practice period for students at class and also at home. Also, Ergin (2013) and Kazemi, Katiraei and Rasekh (2014) offered repeated practice of particular types of sequences (i.e., metadiscourse markers and discipline-specific bundles). The more challenging treatment of the present study may thus explain the partial supporting results.

The study also aimed to investigate whether practicing formulaic sequences in pre-writing activities could promote the learners' autonomy in indentifying other sequences in subsequent readings and using them in writing. The T-test results, however, showed no significant difference between the pre- and post-tests in terms of the number of properly used formulaic sequences in students' writing based on the background readings. The 8-week treatment did not lead to increased use of sequences in the students' writing. This again supports the challenge formulaic language represents for foreign language learners particularly at lower proficiency levels. Learners do not seem to be able to independently identify relevant sequences and use them in subsequent writing despite the treatment period. This comes in line with Čolović-Marković's (2012) study that revealed improvement in the participants' declarative knowledge of formulaic sequences through a C-test after an 8-week treatment period, but failed to find any improvement in the uncontrolled activity of essay writing despite allowing participants' access to the instructional materials used in the treatment period. Enhancing students' autonomous use of formulaic sequences seems to require more elaborate and systematic intervention as was the case in the 16-week dynamic assessment practice of Nasiri and Khorshidi (2015) and the 2-year corpus-driven lexical chunks teaching of Chun-guang (2014).

\section{Pedagogical Implications}

The present study highlights a number of pedagogical implications for foreign writing instruction:

(a) It is recommended to explicitly teach formulaic sequences in pre-writing activities to enhance learners' subsequent writing. This does not rule out the pre-teaching of individual words at the pre-writing stage, but could be jointly addressed in the vocabulary activities.

(b) Formulaic sequences need relatively prolonged practice and recycling. As shown in earlier studies (e.g., Alali and Schmitt, 2012), formulaic sequences might be more challenging to learn.

(c) The number of formulaic sequences cannot be an indicator for effective choice of lexis or writing quality. Quality writing and hence better writing scores are more dependent on how appropriately formulaic sequences are integrated in texts (e.g., Gutiérrez-Colón and Pladevall, 2009-2010).

(d) A principled approach to enhance students' autonomous use of formulaic sequences is needed, particularly for learners of lower proficiency levels. Innovative instructional and assessment approaches (e.g., dynamic assessment and corpus-based instruction) should be carefully considered.

(e) It is essential for instructors to carefully consider the level of vocabulary knowledge they target in their activities and plan their methods and assessment accordingly. For instance, recall is much more challenging than recognition in vocabulary learning. 


\section{Conclusion}

The present study examined the influence of explicit instruction of formulaic sequences in pre-writing vocabulary activities on EFL learners' writing. The results have revealed the positive effect of the explicit instruction on the increased use of formulaic sequences in subsequent writing tasks. The results have also partially supported the positive effect for this instruction on the learners' lexical choices in writing and the overall quality of their writing. The study results, however, failed to show any significantly increased use of formulaic sequences in students' subsequent autonomous story re-writing. These results have been interpreted within the context of the study where the participants were foreign language learners of English with a pre-intermediate level of proficiency and where the participants rewrote news stories while having no access to the original texts and without being required to include vocabulary from the stories in their writing. The study thus supports the incorporation of formulaic sequences in pre-writing vocabulary activities in the foreign language classroom. Explicit instruction of the sequences will be particularly helpful for foreign language learners who seem to face real challenges using appropriate vocabulary in their writing. The introduction and practice of formulaic sequences need innovative and carefully considered methodology to raise learners' awareness of the sequences, build their confidence in using them and promote their autonomy to identify and use relevant sequences on their own. Further research is needed to highlight effective methodology for the explicit instruction of formulaic sequences to support foreign language learners' writing.

\section{Acknowledgement}

The authors extend special thanks to Ms. Saima Rashid, Prince Sultan University, for her great support with the statistical analysis of the paper. Special thanks are also due to Ms. Shazia Khalid, Ms. Nasiya Tahir, Ms. Jenny Khoury and Ms. Alia Rizvi, Prince Sultan University, for implementing the study at their classes.

\section{References}

Abbasian, G-R. (2012). Explicit vs. contrastive-based instruction of formulaic expressions in developing EFL learners' reading ability. The Journal of Applied Linguistics, 5(1), 1-35.

Afzali, H. (2015). The effect of practicing formulaic sequences on speaking fluency of Iranian EFL learners. Indian Journal of Fundamental \& Applied Life Sciences, 5(S4), 330-342.

Alali, F.A. \& Schmitt, N. (2012). Teaching formulaic sequences: The same as or different from teaching single words? TESOL Journal, 3(2), 153-180.

Chen, Y-H. \& Baker, P. (2010). Lexical bundles in L1 and L2 academic writing. Language Learning and Technology, 14(2), 30-49.

Chun-guang, T. (2014). An empirical research on the corpus-driven lexical chunks instruction. International Journal of English Language Teaching, 2(2), 1-36.

Čolović-Marković, J. (2012). The effects of explicit instruction of formulaic sequences on second-language writers. Unpublished doctoral dissertation at the University of Utah, USA. Retrieved from http://content.lib.utah.edu/utils/getfile/collection/etd3/id/2065/filename/2092.pdf.

Conklin, K. \& Schmitt, N. (2008). Formulaic sequences: Are they processed more quickly than nonformulaic language by native and non-native speakers? Applied Linguistics, 29(1), 72-89.

Dastjerdi, H. V. \& Shirzad, M. (2010). The impact of explicit instruction of metadiscourse markers on EFL learners' writing performance. The Journal of Teaching Language Skills, 2(2), 155-174.

Dontcheva-Navratilova, O. (2012). Lexical bundles in academic texts by non-native speakers. Brno Studies in English, $38(2), 37-58$.

Durrant, P. (2008). High frequency collocations and second language learning. Unpublished doctoral dissertation at the University of Nottingham, UK. Retrieved from https://core.ac.uk/download/pdf/98750.pdf.

Ergĭn, I. (2013). The effect of explicit teaching of formulaic language on Turkish English as a foreign language (EFL) learners' writing performance. Unpublished Master's dissertation at Bülkent University, Turkey. Retrieved from: http://www.thesis.bilkent.edu.tr/0006385.pdf.

Erman, B. \& Warren, B. (2000). The idiom principle and the open choice principle. Text, 20(1), $29-62$.

Gómez Burgos, E. (2015). First year university students' use of formulaic sequences in oral and written descriptions. PROFILE Issues in Teachers' Professional Development, 17(1), 25-33.

Gutiérrez-Colón, M. \& Pladevall, E. (2009-2010). Formulaic sequences in the written production of L2 learners of English. Cuad. Invest. Filol., 35-36, 77-104.

Guz, E. (2014). Formulaic sequences as fluency devices in the oral production of native speakers of Polish. Research in Language, 12(2), 113-129.

Jiang, N. \& Nekrasova, T. M. (2007). The processing of formulaic sequences by second language speakers. The Modern Language Journal, 91(3), 433-445. 
Kazemi, M. Katiraei, S. \& Rasekh, A.E. (2014). The impact of teaching lexical bundles on improving Iranian EFL students' writing skill. Procedia-Social and Behavioral Sciences, 98, 864-869.

Koprowski, M. (2005). Investigating the usefulness of lexical phrases in contemporary coursebooks. ELT Journal, 59(4), 322-332.

Latifi, M.A. \& Afraz, S. (2015). The effect of explicit instruction of lexical bundles on developing writing skill in preintermediate EFL learners. International Journal Review of Life Sciences, 5(8), 84-94.

Lewis, M. (1997). Pedagogical implications of the lexical approach. In J. Coady \& T. Hockin (eds): Second Language Vocabulary Acquisition. Cambridge: Cambridge University, 255-270.

Li, J. \& Schmitt, N. (2009). The acquisition of lexical phrases in academic writing: A longitudinal case study. Journal of Second Language Writing, 18, 85-102.

Martinez, R. \& Schmitt, N. (2012). A phrasal expressions list. Applied Linguistics, 33(3), 299-320.

Millar, N. (2011). The processing of malformed formulaic language. Applied Linguistics, 32(2), 129-148.

Mueller, C.M. (2010). Effects of explicit instruction on incidental noticing of metaphorical words sequences during subsequent reading tasks. International Journal of English Studies, 10(1), 81-101.

Murray, L. (2016). An analysis of the usefulness of formulaic sequences and related acquisition exercises in an EFL academic writing textbook. Studies of Language \& Culture, 20, 29-45.

Nasiri, M. \& Khorshidi, S. (2015). Dynamic assessment of formulaic sequences in Iranian EFL learners' writing. International Journal of Language and Applied Linguistics, 1, 26-32.

Ohlrogge, A. (2009). Formulaic expressions in intermediate EFL writing assessment. In R. Corrigan, E. A. Moravcsik, H. Ouali, and K. M. Wheatley (eds): Formulaic Language Volume 2: Acquisition, Loss, Psychological Reality, and Functional Explanations. John Benjamins Publishing Company, 375-86.

Santos, T. (1988). Professors' reactions to the academic writing of nonnative-speaking students, TESOL Quarterly, 22, 69-90.

Shamsaee, S., Hashemi, M. R., Yoonessi, A. \& Ghapanchi, Z. (2015). The effects of teaching mode and L1 phraseological background on learning formulaic sequences. Journal of Applied Linguistics and Language Research, 2(4), 348-362.

Shi, L. \& Wang, L. (2015). A study on the use of lexical chunks by Chinese EFL learners in writing. International Journal of English Linguistics, 5(6), 66-74.

Sinclair, J. (1991). Corpus, Concordance and Collocation. Oxford: Oxford University Press.

Stengers, H., Boers, F., Housen, A., \& Eyckmans, J. (2011). Formulaic sequences and L2 oral proficiency: Does the type of target language influence the association? International Review of Applied Linguistics in Language Teaching (IRAL), 49(4), 321-343.

Wood, D. (2002). Formulaic language in thought and word: Vygotskian perspectives. Cahiers linguistiques d'Ottawa, $30,29-48$

Wray, A. (2000). Formulaic sequences in second language teaching: Principle and practice. Applied Linguistics, 21(4), 463-489.

Xu, Z. \& Zhang, Y. (2015). Strategies used by Chinese EFL learners in processing English formulaic expressions. Polyglossia, 27, 27-38.

Ylisirniö, M. (2012). To be or not to be: A case study of formulaic sequences in Finnish EFL textbooks for upper secondary school. Unpublished Master's dissertation at the University of Jyväskylä, Finland. Retrieved from https://jyx.jyu.fi/dspace/bitstream/handle/123456789/40175/URN\%3ANBN\%3Afi\%3Ajyu-

201211062866.pdf? sequence $=1$

Yonek, L.M. (2008). The effects of rich vocabulary instruction on students' expository writing. Unpublished doctoral dissertation at the University of Pittsburgh, USA. Retrieved from http://dscholarship.pitt.edu/9995/1/yoneklisa122008.pdf.

Zavialova, A. (2015). Explicit instruction of formulaic expressions and second language pragmatic competence: $A$ collective case study. Unpublished Master's dissertation at Carleton University, Canada. Retrieved from https://core.ac.uk/download/pdf/98750.pdf. 


Appendix (A): Sample target vocabulary
\begin{tabular}{|l|l|}
\hline The IW Group & The FS Group \\
\hline detention & separate detention facilities \\
\hline premeditated & premeditated murder \\
\hline judge & appear before a judge \\
\hline tears & break into tears \\
\hline investigation & under investigation \\
\hline asleep & fall asleep \\
\hline charges & face charges \\
\hline autopsy & autopsy results \\
\hline shots & fire several shots \\
\hline viral & go viral \\
\hline violation & serious violation \\
\hline authorities & report the issue to the authorities \\
\hline defense & on the defense \\
\hline suicide & suicide bomber \\
\hline critical & in critical condition \\
\hline condolences & extend condolences \\
\hline ceasefire & reach a ceasefire agreement \\
\hline threats & face death threats \\
\hline campaign & launch a campaign \\
\hline danger & be in danger \\
\hline
\end{tabular}

Appendix (B): Writing Rubric

\begin{tabular}{|c|c|c|c|c|}
\hline Category & 4 & $\mathbf{3}$ & 2 & 1 \\
\hline Content & $\begin{array}{l}\text { All important details } \\
\text { are included. } \\
\text { Demonstrates clear } \\
\text { understanding of } \\
\text { information in the } \\
\text { text. }\end{array}$ & $\begin{array}{l}\text { Important details are } \\
\text { included but some } \\
\text { might be missing. } \\
\text { Demonstrates } \\
\text { adequate } \\
\text { understanding. }\end{array}$ & $\begin{array}{l}\text { Some critical } \\
\text { information is missing. } \\
\text { Demonstrates basic } \\
\text { understanding of } \\
\text { information in text. }\end{array}$ & $\begin{array}{l}\text { Contains only some } \\
\text { details. } \\
\text { Demonstrates little } \\
\text { or no understanding. }\end{array}$ \\
\hline Organization & $\begin{array}{l}\text { Flows logically and } \\
\text { smoothly from } \\
\text { beginning to end. }\end{array}$ & $\begin{array}{l}\text { Flows reasonably } \\
\text { well from beginning } \\
\text { to end. }\end{array}$ & $\begin{array}{l}\text { Somehow confusing or } \\
\text { difficult to follow. }\end{array}$ & $\begin{array}{l}\text { Very confusing or } \\
\text { difficult to follow. }\end{array}$ \\
\hline Word Choice & $\begin{array}{l}\text { Words are correct. } \\
\text { Vocabulary advanced } \\
\text { for level. } \\
\text { Vocabulary is } 100 \% \\
\text { control of the writer. }\end{array}$ & $\begin{array}{l}\text { Words are correct. } \\
\text { Vocabulary adequate } \\
\text { for level. } \\
\text { Few words used out } \\
\text { of control. }\end{array}$ & $\begin{array}{l}\text { Some words used } \\
\text { incorrectly. } \\
\text { Vocabulary appropriate } \\
\text { for level but below } \\
\text { average. } \\
\text { Some loss of control } \\
\text { with vocabulary. }\end{array}$ & $\begin{array}{l}\text { Words used } \\
\text { incorrectly. } \\
\text { Vocabulary below } \\
\text { level. } \\
\text { Vocabulary out of } \\
\text { the writer's control. }\end{array}$ \\
\hline Mechanics & $\begin{array}{l}\text { Excellent grasp of } \\
\text { writing mechanics } \\
\text { Correct usage and } \\
\text { grammar } \\
\text { Writing is complex }\end{array}$ & $\begin{array}{l}\text { Most grammar and } \\
\text { usage correct } \\
\text { Punctuation usually } \\
\text { accurate } \\
\text { Minor corrections } \\
\text { needed }\end{array}$ & $\begin{array}{l}\text { Usage problems } \\
\text { Still distort meaning but } \\
\text { readable to a } \\
\text { sympathetic reader } \\
\text { Punctuation usually } \\
\text { correct } \\
\text { Spelling usually correct } \\
\text { or reasonably phonetic }\end{array}$ & $\begin{array}{l}\text { Grammar or usage } \\
\text { errors very } \\
\text { noticeable. } \\
\text { Punctuation missing. } \\
\text { Frequent spelling } \\
\text { errors. }\end{array}$ \\
\hline $\begin{array}{l}\text { Sentence } \\
\text { Structure }\end{array}$ & $\begin{array}{l}\text { Variety in sentence } \\
\text { structure and sentence } \\
\text { beginnings } \\
\text { Sentences are well } \\
\text { built. }\end{array}$ & $\begin{array}{l}\text { Some variety in } \\
\text { sentence structure } \\
\text { Sentences work } \\
\text { together. }\end{array}$ & $\begin{array}{l}\text { Some variation in } \\
\text { sentence type (simple } \\
\text { and compound } \\
\text { sentences) } \\
\text { Generally short } \\
\text { sentences. }\end{array}$ & $\begin{array}{l}\text { Contains many } \\
\text { fragments and/or } \\
\text { run-on sentences. } \\
\text { Sentences need } \\
\text { work. }\end{array}$ \\
\hline
\end{tabular}

